\title{
A CRÍTICA ZIZEKIANA À CULTURA CONTEMPORÂNEA
}

\section{Ana Carolina Nunes SILVA*}

* Mestra em filosofia pelo Departamento de Filosofia do Instituto de Filosofia, Artes e Cultura da Universidade Federal de Ouro Preto/MG. E-mail: lacarolitanunes@gmail.com.

Artigo submetido em março/2015 e aceito em agosto/2015

DOI: http://dx.doi.org/10.15628/dialektike.2015.2866

\section{RESUMO}

Neste presente trabalho, mostraremos como a impossibilidade de trabalhar com a ideia de "desalienação" que promove a conscientização "sistemática" do que está escondido atrás das aparências enganosas, como pensou a Escola de Frankfurt, explicaria os fenômenos atuais que reconhecemos como razão cínica (a rejeição, a imunização e o "esgotamento da crítica"). Ao contrário da concepção de muitos críticos da ideologia, não lidamos mais com a lógica que anima o famoso comentário de Marx no Capital: "eles não o sabem mas o fazem", mas com um tipo de lógica da socialização em que "os sujeitos sabem muito bem, mas o fazem assim mesmo". Assim como a Teoria Crítica, Žižek também se empenha em uma análise do funcionamento das formas políticas totalitárias, mas por meio desse conceito, pois para o filósofo tais formas totalitárias são a expressão encarnada da servidão voluntária. Com a aliança entre psicanálise e tradição dialética, Žižek encontrou uma forma de fazer uma crítica tal estrutura de racionalidade que encontramos na contemporaneidade, isto é, uma crítica à razão cínica.

PALAVRAS-CHAVE: Slavoj Žižek. Ideologia. Crítica. Capitalismo. Cinismo.

\begin{abstract}
In this paper, we will show how inability to work with an idea of "alienation" that promotes "systematic" awareness of what is hidden behind deceptive appearances, as well as thought the Frankfurt School, could explain the current phenomena we recognize as cynical reason (rejection, immunization and the "empyting of criticism"). Unlike the design of many critics of ideology, we do not deal with logic that animates the famous comment of Marx in the Capital: "they do not know but they do", but with a kind

of logic of socialization in which "the subject know very well, but do it anyway". Just as Critical Theory, Žižek also strives to review the functioning of totalitarian political forms, but through this concept, because for the philosopher such totalitarian forms are embodied expression of voluntary servitude. With the alliance between psychoanalysis and dialectical tradition, Žižek found a way to make such a critical rationality structure we find in contemporary times, that is, a critique of cynical reason.
\end{abstract}

KEYWORDS: Slavoj Žižek. Ideology. Critical theory. Capitalism. Cynicism.

\section{INTRODUÇÃO}

Como filósofo e teórico cultural, o esloveno Slavoj Žižek busca ilustrar em suas análises as contradições do capitalismo contemporâneo e seus espectros ideológicos. Žižek segue uma proposta semelhante àquela feita pelos teóricos da Escola de Frankfurt, isto é, a de 
reintroduzir as descobertas psicanalíticas no interior da história do espírito humano na tentativa de elaborar uma análise da realidade social a partir da "teoria das pulsões", junto com a análise marxista da sociedade. Desse modo, será indispensável em nossa discussão o diálogo com a crítica cultural dos pensadores frankfurtianos e a relação destes com o conceito de cinismo.

A perspectiva zizekiana sobre o cinismo é oriunda das reflexões de Peter Sloterdijk (que também têm suas vertentes na Teoria Crítica Social) em a Crítica da Razão Cínica (1983), uma polêmica obra publicada dias depois de comemorado o ducentésimo aniversário da publicação da Crítica da Razão Pura (1781), de Immanuel Kant. Essa obra consiste em uma meditação sobre a sentença "saber é poder"; é uma reflexão sobre o esgotamento da relação entre teoria e práxis, ideal e realidade efetiva, que diagnostica em uma palavra que o "saber" no Esclarecimento tornou-se dogmático.

Conforme a tese que admite que só podemos conhecer aquilo que está no domínio da experiência (os fenômenos) e não a realidade em si (a Coisa-em-si), Kant limitou o conhecimento de forma a abrir a possibilidade de promover o devir, pois sabia que isso só seria possível com a crença. Nesse viés, o cinismo funciona como uma desmistificação que gera uma espécie de interrupção desse devir, ou seja, nada pode ainda acontecer, nada pode ser mudado.

Segundo Sloterdijk, somente com uma "crítica da razão cínica" o Esclarecimento pode se renovar e permanecer em seu projeto de transformar o "ser" por meio da consciência. Com a difusão do cinismo e sua transformação em mentalidade coletiva, as bases morais tradicionais da crítica à ideologia entraram em colapso. Hoje ficamos com a mensagem de um futurismo negativo, é com o que é pior: uma realidade quase necessária. Quanto mais uma sociedade se vê sem alternativas, mais ela se orienta por uma racionalidade cínica.

Nesse livro, Sloterdjik defende também a necessidade de pensar o "fenômeno cínico" como estratégia prática para pensar a ideologia sob sua forma atual:

O mal-estar na cultura assumiu uma nova qualidade: ele aparece como um difuso cinismo universal. A crítica à ideologia tradicional está atônita diante dele. Ela não vê na consciência cinicamente desperta um ponto de partida para o esclarecimento. O cinismo moderno apresenta-se como o estado de consciência que se segue às ideologias ingênuas e o esclarecimento dessas ideologias. Nele o esgotamento gritante da crítica ideológica tem a sua razão de ser. Tal crítica permaneceu mais ingênua do que a consciência que ela quis desmascarar; em sua racionalidade bem-comportada, ela não acompanhou as mudanças da consciência moderna rumo a um realismo 
múltiplo e refinado. A sequência de formas da falsa consciência até agora mentira, erro, ideologia - está incompleta; a mentalidade atual força o acréscimo de uma quarta estrutura - a do fenômeno cínico. Falar de cinismo significa tentar adentrar a antiga estrutura à ideologia por outro acesso (SLOTERDIJK, 2012, p. 31).

Na filosofia de Žižek encontramos a abordagem do cinismo em nosso tempo não como um problema de ordem moral, mas como um padrão de racionalidade de um tempo que conhece os pressupostos ideológicos anteriormente ocultos pelo universal ideológico e que não encontrou muita razão para reorientar sua racionalidade. Em outras palavras, a ideologia cínica se apresenta como uma nudez que já não desmascara porque é uma mentira que se põe como verdade.

\section{A IDEOLOGIA CÍNICA OU A FALSA CONSCIÊNCIA ESCLARECIDA}

Marx compreendia a ideologia como uma "falsa consciência" no domínio das relações reificadas que constituem uma aparência socialmente necessária e como uma "alienação" incapaz de compreender a totalidade das estruturas causais que suportam as reproduções sociais. Ou seja, a ideologia obnubilaria as condições reais que guiam a vida social, pois é um aparato importante da constituição do poder político, econômico e cultural da classe dominante. Portanto, a célebre frase de Marx em O Capital (1867), "Eles não o sabem, mas o fazem" ", tornou-se "Eles o sabem, e mesmo assim o fazem": esta é a fórmula contemporânea da ideologia cínica.

Isso significa que estamos perfeitamente cientes da falsidade, da particularidade por trás da universalidade ideológica, mas mesmo assim nos mantemos presos a ela em nome de uma aparente autoproteção, ou como forma de negociar as demandas paradoxais da realidade efetiva. Vejamos um exemplo em que Žižek nos alerta para uma certa ingenuidade que compõe (ou constitui) a ideologia burguesa:

a universalidade ideológica, a noção ideológica da "liberdade" burguesa compreende, inclui uma certa liberdade - a que tem o trabalhador de vender sua força de trabalho -, liberdade esta que é a própria forma de sua escravidão; do mesmo modo, a relação de troca funciona, no caso da troca entre a força de trabalho e o capital, como a própria forma da exploração (ŽIŽEK, 1992, p. 59).

\footnotetext{
${ }^{1}$ MARX, K. "O caráter fetichista da mercadoria e seus segredos". In: O Capital: crítica da economia política. p, 200.
} 
Na visão marxista tradicional, a "crítica", entendida como uma "leitura sintomal" da realidade social, poderia instaurar um regime de relações "não-reificadas", trazendo à cena os mecanismos ideológicos que produzem sentido para nossa realidade. No entanto, o cinismo já se apresenta como uma nudez que não mais se desmascara e, portanto, não há como subverter a "consciência cínica" com uma leitura que tente confrontar o discurso ideológico "superficial" com um discurso coerente, a fim de identificar pontos de incoerência.

Vivemos um momento em que se conhecem os pressupostos ideológicos que determinavam a ação "alienada", mas não encontrou muita "razão" para reorientar a "razão para agir". O cinismo, enquanto ideologia reflexiva, exprime de maneira adequada a mortificação da crítica, pois ela é a

consciência infeliz modernizada, da qual o Esclarecimento se ocupa ao mesmo tempo com êxito e em vão. Ele aprendeu sua lição sobre o Esclarecimento, mas não a consumou, nem a pôde consumar. Ao mesmo tempo bem instituída e miserável, essa consciência não se sente mais aturdida por nenhuma consciência ideológica; sua falsidade já está reflexivamente conformada (SLOTERDIJK, 2012, p. 34).

Podemos perceber, assim, que o cinismo aparece como elemento maior do diagnóstico de uma época na qual o poder não teme a crítica que desvela seu mecanismo ideológico, pois aprendeu a zombar de si mesmo, o que lhe permitiu revelar o segredo de seu funcionamento através de um "autodesmentir" que continua funcionando do mesmo modo. Isto é, para além dos ocupantes de cargos públicos e dos estamentos burocráticos, nossa época experimenta a difusão de um modelo de subjetividade que aprendeu a deixar a consciência de si sem que isso tenha nenhum efeito sobre si. Afinal, no cinismo as subjetividades estão cindidas, pois de outro modo não teríamos como obter essa distancia irônica e tampouco aceitar tal transgressão. "Diante do enriquecimento ilícito, do roubo, do assalto, a reação cínica consiste em afirmar que o enriquecimento legítimo é um assalto muito mais eficaz do que o assalto criminoso." (ŽIŽEK, 1992, p. 60).

Devemos entender o termo "cinismo" no capitalismo contemporâneo não como um problema de ordem moral, mas como um problema geral que promove mudanças nas estruturas de racionalidade e nos critérios normativos da vida social. Como podemos perceber, o termo "falsa consciência esclarecida" já nos traz um sentido paradoxal no próprio termo, pois tal cinismo pautou-se por uma estrutura ambígua na qual lei e transgressão 
caminham conjuntamente ${ }^{2}$. A racionalidade cínica é um regime cuja denúncia não pode mais servir para desqualificar a dimensão paradoxal dos discursos. Portanto, essa denúncia deixa de ser a potência da crítica, já que a realização paradoxal do discurso é, de certa forma, realização legítima ${ }^{3}$. Além disso, o cinismo nos mostrou que condições transcendentais normativas de julgamento podem ser seguidas a partir de sua perversão, sem contradizer a relação entre ato e julgamento. A citação a seguir começa com uma espécie de "pergunta exclamativa", ou pelo menos, com uma espécie de interjeição da linguagem falada:

Ora, mas será que devemos dizer que, com a "consciência cínica", saímos do campo ideológico propriamente dito e entramos no universo pós-ideológico em que um sistema ideológico se reduz a um simples meio de manipulação, que não é levado a sério nem mesmo por seus inventores $\mathrm{e}$ propagadores?(ŽIŽEK, 1992, p. 61)

Devemos entender os cínicos do presente como indivíduos melancólicos que buscam controlar seus sintomas depressivos através de meras recompensas da cultura para poderem permanecer no mundo da "vida falsa". Contudo, eles não são tolos, eles sabem o que fazem, pois, como já dizia Sloterdijk, eles "o fazem porque as ramificações objetivas e os impulsos de autoconservação, a curto prazo, falam a mesma língua e lhes dizem que, se assim é, assim deveria ser" (SLOTERDIJK, 2012, p. 33). Em outras palavras, estamos diante da falsa consciência esclarecida ou da inocência perdida, pois ela compreende ser vítima do poder que lhe impõe sacrifícios, mas continua a se submeter.

\section{A LASSIDÃO DA ESCOLA DE FRANKFURT NA CRÍTICA SLOTERDIJKIANA DO CINISMO DAS MASSAS}

\footnotetext{
${ }^{2}$ Caminham juntas sem parecer contraditórias porque há uma divisão subjetiva; esse aspecto será mais bem tratado adiante, em nossa abordagem do fetichismo.

3 Paralelamente a Žižek, Giorgio Agamben também se atentou para o mesmo problema, o que o levou a recuperar o conceito de "Estado de Exceção" cunhado por Carl Schimdt e também a concepção de Walter Benjamin sobre esse conceito como forma de entender a democracia liberal no capitalismo contemporâneo. Segundo Agamben, na contemporaneidade há uma consolidação de um novo paradigma de governo, que é o estado de exceção. O filósofo busca fazer essa análise em contexto histórico: o Senado Romano, a Revolução Francesa, as duas grandes guerras mundiais e o Onze de Setembro. O estado de exceção é uma espécie de zona "vazia" que se instala a partir do momento em que um chefe de governo assume o poder de acordo com a constituição vigente e suspende a aplicação das normas constitucionais para implantar uma outra ordem jurídica. Como exemplo, o Estado nazista, em que Hitler, ao assumir o poder, promulgou o "Decreto para proteção do povo e do Estado que suspendia os artigos da constituição de Weimar, relativos a liberdades individuais" (AGAMBEN, 2007).
} 
A articulação ideológica na razão cínica se dá através da estetização da política, da cultura e das relações intersubjetivas que, por sua vez, nada mais são que outra face ideológica de uma nova forma de disseminação assumida pelo capital em nosso tempo. A construção da noção moderna de "estética" é assim inseparável da construção de formas ideológicas dominantes da sociedade de classes moderna, e, na verdade, de todo um novo formato da subjetividade apropriado a esta ordem social A ideologia não é apenas um "falso universal", mas também a produção de "falsos particulares"; desse modo, a reflexão ideológica no campo da estética é de suma importância, pois é justamente nesse espaço que a categoria do "particular" tem predominância (EAGLETON, 1993).

Em função de sua contradição, a estética constitui um desafio perante as ideologias dominantes. Sua emergência como categoria teórica acha-se intimamente articulada com o processo material pelo qual a produção cultural, num estágio inicial da sociedade burguesa, ganhou "autonomia" em relação às várias funções sociais a que servia tradicionalmente. A estética é o protótipo secreto da subjetividade na sociedade capitalista incipiente, e ao mesmo tempo a visão radical das potências humanas como fim em si mesmas, o que a torna inimigo implacável de todo pensamento dominador ou instrumental. Ela representa uma preocupação com o particular concreto, de um lado, e de outro com a astuciosa forma de universalismo (EAGLETON, 1993, p.12).

Seguindo o comentário de Eagleton, observaremos que, no âmbito da cultura o conceito de "Indústria Cultural", compreendido como um modo de organização, é uma grande construção/contribuição conceitual de Adorno e Horkheimer para analisarmos esse esvaziamento da crítica e os modos de operação da ideologia em prol de uma racionalidade cínica.

Em A indústria cultural: o esclarecimento como mistificação das massas, Adorno e Horkheimer nos mostram como, nos dramas cinematográficos, padrões e comportamentos de pseudossujeitos com seus pseudoconflitos são assimilados socialmente. Esses aspectos são tão atuais que hoje podemos perceber esses ditames nas telenovelas, seriados e reality shows. Nesse esquema permanente de adequação da estrutura social, acontece o que os filósofos frankfurtianos denominaram de "coisificação" ou "reificação" dos indivíduos, isto é, a partir desse processo, os indivíduos são tratados como meras coisas ${ }^{4}$.

\footnotetext{
${ }^{4}$ Com as teorias político-econômicas elaboradas por Marx, nos inteiramos de que, para a manutenção e reprodução do sistema capitalista, é necessário ultrapassar o âmbito econômico em prol de seu desenvolvimento. Observando tal fenômeno, os teóricos frankfurtianos viram a Indústria Cultural como resistência; ela manteria o
} 
Diante desse quadro, os teóricos-críticos da cultura buscaram apreender criticamente o conceito de Indústria Cultural como forma de interromper sua totalização e continuidade, para restaurar a possibilidade de uma sociedade humanizada. A tarefa de crítica seria uma forma de anunciar uma "verdade" não realizada na realidade efetiva, isto é, trazer à tona a fraude de uma racionalidade falsa e manipuladora, reflexo de uma irracionalidade objetiva da sociedade.

$\mathrm{Na}$ contemporaneidade, o combate que parecia provável através da ruptura da imposição social objetiva se revela obstruído e improvável, pois a contradição que colocaria o capital em contradição, como afirmou Marx, é suspendida e vivida pela Indústria Cultural em seu dinamismo e persistência. Mas o projeto de resgate do "primado do objeto" pela dialética, projeto este elaborado pela Teoria Crítica e que parecia descortinar universos inteiros, hoje permanece vazio. Mesmo com todas as cortinas abertas, o fantasma da Indústria Cultural prevalece em sua forma mais paradoxal na contemporaneidade, e é por isso que ele está sendo questionado em nosso atual estado de coisas. A Indústria Cultural é a anulação da crítica, tanto que a própria "crítica cultural" à indústria cultural se converteu em "Indústria da Cultura". É por isso que Žižek enxerga o cinema como um lugar privilegiado de compreensão dos mecanismos ideológicos, pois consegue estetizar as formas de transgredir suas regras "secretas".

Tanto o pensamento de Žižek quanto o de Sloterdijk são oriundos das vertentes da Teoria Crítica da Sociedade. No entanto, na Crítica da Razão Cínica, Sloterdijk dedica-se à realização de uma crítica "ácida" aos teóricos frankfurtianos e detecta em suas teorias o cinismo de nosso tempo, o qual busca combater. Segundo o filósofo, o conceito de "crítica" compreendido como um ponto de desconforto no tecido sociocultural nunca havia se tornado tão necessário em nosso tempo. No entanto, a concepção benjaminiana do conceito como “correta distância" (BENJAMIN, 1995, p.54) transformou-se em um abismo diante de tal subjetividade cindida própria ao cinismo. Ou seja, não há como obter uma distância entre o sujeito que critica e aquilo que é criticado, pois o cinismo é uma correta distância de si mesma. Tal distância é tão excessiva que nenhuma faculdade cognitiva é capaz de lidar com um fenômeno tão complexo e paradoxal.

capital como "contradição da contradição" existente. A Indústria Cultural foi um aparato ideológico para o sustentáculo dos regimes fascistas, e na contemporaneidade está aliada à democracia liberal, pois a práxis política desse sistema baseia-se na administração e no apaziguamento de conflitos entre ideologias e ideias. 
Vivemos uma espécie de "autorrenúncia" da crítica em todas as esferas da vida social que, por sua vez, mostraram-se integralmente indiferentes a esse acontecimento. Em outras palavras, os críticos se fundiram com o criticado, e toda e qualquer distância que teria sido criada pela moral foi perdida por meio da indiferença geral em meio à imoralidade ou à "moral do mal menor", adotando todos os padrões essenciais da crítica e do procedimento de desmascaramento. Nesse ínterim, discutir o conceito de "cinismo" é o mesmo que expor um escândalo moral à crítica.

\section{O QUE A CRÍTICA PODE AINDA REALIZAR?}

Para Sloterdijk, em um sistema onde os indivíduos são colocados, ao mesmo tempo, em uma situação de "prisão" e "caos", isto é, onde não há fronteiras entre a crítica e o criticado, a perspectiva central de uma crítica concludente parece impossível: ao invés de uma "correta distância", a crítica necessitaria de uma "proximidade correta" 5 . Para ele, os teóricos frankfurtianos se esforçaram somente na produção de pensamentos baseados em um a priori da dor (SLOTERDIJK, 2012, p.20), isto é, acreditavam que, a partir de uma certa "dor do mundo", poderíamos distinguir o verdadeiro do falso e, com isso, a crítica poderia ser orientada por essa instância. E ainda, suas ideias resultavam em teorias calcadas no "desprezo" e na "revolta" com tudo que estivesse relacionado ao poder, mas que permaneciam na desesperança em relação a qualquer tipo de mudança profunda da realidade social e, ao mesmo tempo, não se conformavam com sua realidade efetiva.

Ora, permanecer no plano crítico por meio de uma sensibilidade que buscava chegar às coisas mesmas era somente uma mera questão utópica, pois não vale a pena manter os sentidos apurados para uma felicidade que nunca virá. Assim, a crítica ao Esclarecimento desaguou em desilusão cínica e mostrou o quanto pode ser entediante e inútil uma mobilização teórica ${ }^{6}$. Quem pode ainda ser o esclarecedor? Como poderíamos nos engajar hoje?

\footnotetext{
${ }^{5}$ Apesar de direcionar uma crítica ao projeto frankfurtiano de renovação da sensibilidade como transformação social, Sloterdijk compartilha de algumas ideias dos teóricos, na medida em que igualmente reconhece que há uma "verdade" recalcada que é incompreensível sem a automediação da esfera do sensível. Portanto, na crítica social se faz necessária uma teoria da comunicação e uma análise da cultura de massa como forma de trazer à tona essa verdade, já que as tentativas de fundamentar uma verdade universal pela razão instrumental mostrou-se um álibi dessa mesma alienação dos indivíduos na vida social.

${ }^{6}$ Neste ponto vale ressaltar um certo exagero da crítica de Sloterdijk à "Teoria Crítica”, pois Walter Benjamin, em suas análises sobre a "reprodutibilidade técnica", buscou fundamentar pontos positivos e negativos do
} 
Não muito tempo antes da morte de Adorno, houve uma cena em um auditório da Universidade de Frankfurt que se ajusta como uma chave à análise do cinismo aqui iniciada. O filósofo estava justamente em vias de começar sua preleção, quando um grupo de manifestantes impediu-o de subir ao tablado. Algo desse gênero não era incomum no ano de 1969. Nesse caso, porém, algo obrigou as pessoas olharem mais atentamente. Entre os desordeiros se fizeram notar algumas estudantes que, em protesto desnudaram seus seios diante do pensador. De um lado se achava a carne nua, que exercia uma "crítica", de outro um homem amargamente desiludido, sem que praticamente nenhum dos presentes tivesse experimentado o significado de crítica - cinismo em ação. Não foi a violência da nudez. Justo e injusto, verdadeiro e falso foram misturados nessa cena de maneira inextrincável, de uma maneira que é pura e simplesmente típica para os cinismos. O cinismo ousa se mostrar com verdades nuas, que mantêm algo falso no modo como são expostas (SLOTERDIJK, 2012, p, 26).

Ao contrário de Sloterdijk, Žižek busca pensar como poderíamos deixar as expectativas de desvelamento ideológico sem voltarmos ao cinismo. Ele enxerga e retoma algumas contribuições importantes da Escola de Frankfurt, principalmente no que diz respeito à análise socioeconômica de acordo com a teoria das pulsões. Além de suas vertentes oriundas da Escola de Frankfurt e da filosofia sloterdijkiana na crítica ao cinismo, Žižek faz também uma articulação entre as formulações psicanalíticas de Jacques Lacan e a tradição dialética hegeliana. Tal articulação tem como propósito a formulação de uma nova teoria do sujeito, capaz de fornecer uma nova estrutura de crítica ao estado de coisas de nosso sistema atual.

Entretanto, para Žižek a única "falha" dos teóricos da Escola de Frankfurt foi permanecer à espera de uma elucidação da regressão e do comportamento "automático" capaz de promover a "desalienação". Apesar de sua "rejeição" do pensamento frankfurtiano, Sloterdijk também pensa uma espécie de "desalienação" com o resgate da concepção do cinismo antigo. Mas a crítica à racionalidade cínica na filosofia zizekiana toma outros parâmetros. Ao contrário de Sloterdijk, para Žižek o cinismo não somente mostrou a obsolescência de tal projeto de transformação social como também demonstrou que a ideologia opera de forma cada vez mais fetichista.

No entanto, o filósofo esloveno pensa a ideologia do capitalismo contemporâneo na esteira do conceito marcusiano de "dessublimação repressiva" 7 cujo conceito se destaca na

processo de refuncionalização da arte na sociedade moderna.

${ }^{7} \mathrm{O}$ conceito de "dessublimação repressiva" cunhado pelo filósofo Herbert Marcuse nos permite compreender a dinâmica da sociedade contemporânea que, por um lado, possibilita uma maior "liberdade" e satisfação das necessidades, ao mesmo tempo que essa "liberdade" atua como poderoso instrumento de dominação, sendo 
contribuição do filósofo para a teoria freudiana das pulsões: a "dessublimação" é a realização imediata dos desejos. Vejamos em que consiste essa contribuição a partir de uma retomada do conceito freudiano, antes de analisarmos o modo como Žižek refina essa mesma retomada.

\section{5 ŽIŽEK E MARCUSE NA RETOMADA DA TEORIA DAS PULSÕES.}

Freud definiu o conceito de "sublimação" como um modo de o indivíduo lidar com a civilização, com os traços que mais sobressaem no desenvolvimento cultural dos seres civilizados. A sublimação é um processo de desvio das "pulsões" que não podem ser integradas na ordem social, pois consiste no fato de que a pulsão se dirige para outro objetivo, como a arte, por exemplo.

O conceito de "dessublimação repressiva" 8 é cunhado por Herbert Marcuse como forma de entendermos o funcionamento das sociedades totalitárias, isto é, esse conceito denominava o enfraquecimento do Eu na instrumentalização das pulsões. Para Marcuse, há uma neutralização do conflito entre o "princípio de prazer" e o "princípio de realidade" por meio de uma satisfação administrada, isto é, uma satisfação obtida com aquilo que a sociedade oferece. Tal aspecto traduz fielmente a lógica da reprodução do capital pelo que Žižek chamará de imperativo do gozo.

$\mathrm{Na}$ passagem do capitalismo de produção para a sociedade de consumo, a figura social do Supereu foi invertida. O gozo hoje tornou-se um dos motores de circulação de mercadorias na sociedade de consumo. O Supereu na contemporaneidade não está mais vinculado à repressão das pulsões, assim como apontou Freud, mas com a obrigação de gozar nos processos de socialização. Ou seja, agora temos o gozo como imperativo: Goze!

Para Žižek a "liberdade" da dinâmica do capitalismo contemporâneo é o imperativo do gozo. Através do conceito lacaniano de "gozo" o filósofo vê uma chave de leitura da lógica da sociedade de consumo, pois, como já foi mencionado, Žižek enxerga uma relação recíproca entre "pulsões" e "reprodução econômica". Devemos entender o conceito de "gozo"

absorvida pelo sistema ao adquirir a função de manipulação e controle dos indivíduos, de suas consciências, de seus desejos.

${ }^{8}$ Ao contrário do conceito de sublimação, a "dessublimação repressiva", por sua vez, é a realização imediata dos desejos. Com isso, a "sublimação desrepressiva" seria, para Marcuse, uma forma de desviar aquela pulsão que não encontrou lugar na realidade social para se realizar em outra instância. De acordo com o pensamento marcusiano, a dimensão estética da arte seria essa instância que poderia proporcionar a realização dos desejos que não encontraram espaço no mundo da vida. 
como uma instância de satisfação mórbida que não leva mais em conta os sistemas de defesa e controle do $\mathrm{Eu}^{9}$.

É curioso observar como essa reflexão também levaria Marcuse a abordar o conceito de cinismo. Segundo ele, temos aí o:

Cinismo: porque nenhuma ideologia é capaz de esconder o fato de que essa classe dominante já não está desenvolvendo as forças produtivas outrora contidas nessas instituições, mas limita-se a prender e a difamar. A ideologia retira-se da superestrutura (onde foi substituída por um sistema de mentiras e absurdos gritantes) e passa a incorporar-se nos bens de consumo e serviços da sociedade de consumo, sustentáculo de uma falsa consciência de vida boa (MARCUSE, 1973, p. 87).

A partir das apropriações das teorias freudianas feitas por Marcuse, podemos perceber que a grande astúcia da psicanálise foi detectar uma nova forma de repressão por meio da "nãosublimação", isto é, mostrar que o Supereu na contemporaneidade está ligado à "nãorepressão", ao imperativo de gozar. O cinismo, para Žižek, duplicou a estrutura da Lei simbólica e é o sintoma da sociedade sem culpa, já que os indivíduos nessa ordem podem portar disposições contraditórias. É por isso que as leis da sociedade cínica atuam de forma flexível, para que os sujeitos não passem por cima de seu gozo e que ainda possam vivenciálo, ao mesmo tempo, obedecendo a toda uma lógica de consumo. Ou seja, nessa nova ordem do Supereu, os indivíduos podem seguir as Leis do imperativo do gozo - não abrir mão de seu gozo - sem entrar em conflito com as leis da esfera sociocultural.

Segundo Žižek, a "utopia" que emerge em nosso atual contexto é: "você pode tudo, pode ir até o fim e satisfazer todos os seus desejos"; mas na verdade isso não acontece, e é o que ele chamou de ideologia cínico-permissiva. Cínica porque o próprio sistema sabe de todas as restrições da fórmula ideológica, mas mesmo assim acredita nela para lidar com tais antagonismos.

Žižek detecta, em certos produtos desprovidos de sua substância nociva que são oferecidos na cultura capitalista, essa "falsa permissividade" na qual vivemos, como, por exemplo, na cerveja sem álcool, no café sem cafeína, no cigarro sem nicotina etc. Isto é, há

\footnotetext{
${ }^{9}$ Com uma análise sobre a origem da consciência moral e da internalização da lei simbólica (família, Estado e religião), Freud denominou os processos de civilização como uma espécie de renúncia pulsional. Tal renúncia se dá por meio de uma estrutura simbólica que dita as leis que devem atuar sobre os indivíduos, o que ele denominou de Supereu. Nessa análise, Freud detectou que a culpa é o grande problema do desenvolvimento da civilização, e os modos de internalização da Lei através do Supereu consistem exatamente em mostrar como dinâmicas de repressão se transformam em modo neurótico de satisfação, ou seja, em mostrar como aquilo que nos adoece pode ser também fonte de gozo.
} 
uma ética que, por um lado, permite o consumo ilimitado, sem moderação, mas isso ocorre porque o objeto é em si privado de sua substância nociva; consumimos "como se" fosse o produto com todos os seus reais componentes.

O principio ético "consuma, mas com moderação" tornou-se "consuma o quanto quiser". Este é o paradoxo que confrontamos hoje: “desfrutamos" de uma permissividade que nada mais é que seu oposto. Em consequência disso, por exemplo, a própria frase de Hélio Oiticica, "seja marginal, seja herói", não é mais algo altamente subversivo em nossa atualidade, pois vivemos em uma era em que ser "marginal" ou "transgressor" faz parte da cultura dominante. Para Žižek isso acontece porque o próprio sistema demanda essa "transgressão":

Acho muito difícil ser marginal. Nós vivemos uma época paradoxal, e pensei nisso em Londres, sobre o que significa ser marginal e subversivo na pintura e na escultura, por exemplo. Tenho um amigo londrino que está pintando e queria fazer uma exposição na Saatchi, uma grande galeria que apoia os marginais, e disseram para ele: "mas isso é só pintura!" O que está em voga hoje, em Londres, é o que envolve escândalo: urinar na pintura ou numa estátua de Jesus Cristo, fazer um vídeo de uma colonoscopia.... ${ }^{10}$

Qual é o lugar da crítica em uma sociedade em que todos têm o direito de gozar? Tal problema apontado na passagem supracitada reside no fato de que esse gozo é impossível de ser satisfeito. Ou seja, o sujeito nunca atingirá o gozo ilimitado, apesar de não medir esforços para atingi-lo, e sempre permanecerá insatisfeito. É por isso que tal instância tornou-se uma ferramenta da engrenagem da sociedade de consumo. A Indústria Cultural, por exemplo, é um grande álibi desse fenômeno, incitando o consumo exacerbado. É por isso que as mercadorias tornaram-se cada vez mais descartáveis e rápidas, pois a frustração com o fetiche da mercadoria produz uma nova mercadoria. Tal aspecto assinala a passagem de uma sociedade da satisfação administrada para uma sociedade da insatisfação ilimitada na qual ninguém realmente acredita nas promessas de gozo oferecidas pelo sistema da mercadoria, ou seja, o que vemos surgir daí é uma espécie de "cinismo da mercadoria".

\section{O FETICHISMO SEM OBJETO: O CARÁTER SUBLIME DA IDEOLOGIA.}

10 Comentário feito na entrevista "Sonhando perigosamente com Slavoj Žižek, por Rogério Bettoni em 02/12/2012”. Disponível em: http://slavoj-zizek.blogspot.com.br/ 
Em uma conferência no Brasil em 2004, Slavoj Žižek afirmou que, se quisermos visualizar ou criticar os mecanismos ideológicos em nosso atual estado de coisas, devemos direcionar nossa análise para um estranho fenômeno: o fetichismo sem seu objeto. Ora, isto significa que temos ideologia sem ideologia? Longe de seguir este "mantra pós-moderno", Slavoj Žižek afirma que a ideologia continua mais viva do que nunca. Afinal, assim como já definira Marx, ela é algo "falso" e "incompreensível": a ideologia é uma construção fantasmática, sublime, isto é, “indestrutível e imutável” (ŽIŽEK, 1999, p.303), que pode se perpetuar até mesmo em contextos ditos pós-ideológicos. Antes de chegarmos a este cerne da filosofia zizekiana, veremos o conceito de "fetichismo" retomado por Marx e Freud como forma de auxiliar a compreensão dos modos de operação da ideologia no capitalismo contemporâneo ${ }^{11}$.

$\mathrm{Na}$ sociedade moderna capitalista, o fetichismo transformou-se em dispositivo de crítica de seus processos de socialização, seja no mundo do trabalho, destacado por Marx, seja no campo das pulsões, como assinalou Freud. Tais teorias mostraram que a racionalidade instrumental da sociedade moderna é tão encantada quanto qualquer outra sociedade primitiva. Será a partir dessa incapacidade de passar dos objetos sensíveis ao domínio conceitual, própria do pensamento primitivo, que Marx formulará sua tese sobre o fetichismo da mercadoria e do desconhecimento ideológico: "Eles não o sabem, mas o fazem". O conceito de fetichismo passou a ser considerado também como chave de leitura de uma forma de encantamento presente no núcleo de nossa sociedade contemporânea.

\section{A IDEOLOGIA CÍNICA COMO "DESMENTIDO FETICHISTA".}

Freud, por sua vez, ao se debruçar sobre o funcionamento da crença, observou uma dissociação entre saber e crença, implicando profundas transformações no sentido do fetichismo como tomado na tradição iluminista. Compreendido desse modo, o conceito de

\footnotetext{
11 "Enunciado pela primeira vez em 1756 pelo escritor francês Charles de Brosses, membro da Académie des Inscriptions et Belle-Lettres de Paris e colaborador da Enciclopédia de Diderot e d'Alambert, o fetichismo aparecia como peça maior de uma operação que visava a estabelecer os limites precisos entre nossas sociedades esclarecidas e as sociedades primitivas pretensamente vítimas de um sistema encantado de crenças supersticiosas". (...) À ocasião, o fetichismo aparecia definido, fundamentalmente, como culto de objetos inanimados e, em outros casos, como divinização de animais e de fenômenos irregulares da natureza. Baseandose no relato de navegadores portugueses a respeito do modo de culto de tribos africanas da Guiné e da África Ocidental, De Brosses criou um termo derivado do português antigo fetisso (que dará no atual feitiço) a fim de pôr em marcha uma generalização extensa que englobava esses espaços infinitos nos quais o Ocidente não via sua própria imagem. (SAFATLE, 2010, p. 21).
}

Dialektiké. Ano 2, v. 2, out 2015, p. 50-70 | Revista de Filosofia 


\section{SILVA, Ana Carolina Nunes (2015)}

fetichismo permitiu a Freud apontar um aspecto fundamental da estrutura funcional do Eu moderno, a saber, a clivagem (Spaltung). Em Freud, devemos entender esse conceito como um modo peculiar de suspensão dos conflitos entre o "princípio de prazer" e o "princípio de realidade", denominado clivagem do Eu.

Isto significa que, devido às necessidades de desempenhar certas funções sociais pelo "princípio de realidade" e devido à frustação com certos modos de procura de satisfação pulsional do "princípio de prazer", o Eu seria obrigado a recorrer à função fantasmática do fetichismo como um modo de síntese psíquica para defender-se de seu desejo. O Eu aparece como resultado de uma formação paradoxal de compromissos construída sobre uma estrutura de contrariedades. Ou seja, o Eu deve dividir-se a fim de assegurar seu trabalho de unificação das moções pulsionais e impor-se como unidade. Na contemporaneidade, percebemos uma relação intrínseca entre tais estruturas duais e o fetichismo, pois não há como fazer a dissociação entre um "sistema de crenças" e uma "sociedade desencantada". Essa operação de desencantamento, longe de ser o fim da crença, será condição para que a crença permaneça, mas agora envolvida numa instância do "saber". Esse aspecto mostrou a necessidade funcional da ilusão social como componente fundamental do vínculo social, pois nesse espaço os sujeitos podem agir como se soubessem: "eu bem sei, mas mesmo assim..."; esta é a fórmula que representa aspectos fundamentais do modo de relação entre crença e saber que encontramos de maneira exemplar no desmentido fetichista, no processo de desencantamento da sociedade contemporânea.

Apesar do conceito de fetichismo aparecer em vários trechos da obra de Freud, a começar pelos Três ensaios sobre a teoria da sexualidade (1905), ele só foi tratado realmente de modo mais enfático em dois pequenos textos: no artigo Fetichismo (1927) e no texto de 1938 sobre a Divisão do Ego no processo de defesa. Para uma melhor compreensão da teoria do fetichismo em Freud, é necessário que se entenda o mecanismo do "desmentido" (Verleugnung). O curioso na lógica do fetichismo é que não se trata de expulsar nem recalcar, por exemplo, a castração, mas sim de ter um saber sobre ela, pois a ideia do fetiche é uma espécie de contradição que pode conciliar duas afirmações incompatíveis.

No texto em que nos explica a chamada Spaltung, ou a Divisão do ego no processo de defesa (1938), Freud observa que a descoberta da diferença anatômica entre os sexos coincide com a ameaça de castração. Tentando evitar a constatação da inexistência do órgão fálico nas mulheres, o menino mantém a crença de que talvez as mulheres mais velhas e 
respeitáveis, como sua mãe, ainda sejam dotadas de pênis. Entretanto, no momento em que procura certificar-se de sua existência, as crianças produzem uma espécie de deslocamento do valor através do fetiche. Segundo Freud,

o menino não contradisse simplesmente suas percepções e alucinou um pênis onde nada havia a ser visto; ele não fez mais do que um deslocamento de valor - transferiu a importância do pênis para outra parte do corpo, procedimento em que foi auxiliado pelo mecanismo de regressão. (FREUD, 1987c, p. 311).

Safatle salienta o fato de que Freud, com sua teoria do "desmentido" (Verleugnung), encontrou uma definição lógica, ou estrutural, da perversão, sem precisar partir da mera descrição de sintomas. Com isso, a psicanálise mostrou-se capaz de produzir articulação entre as posições estruturais do sujeito frente a seu desejo. Para ele, essa capacidade de manter duas ideias opostas na mente seria fundamental para explicar a percepção de Freud de uma mutação, cada vez mais perceptível no processo de socialização e individualização das sociedades modernas. Isto significa que Freud já teria se conscientizado de que a perversão estaria se transformando em modo hegemônico de socialização dos desejos na sociedade contemporânea. Segundo Safatle,

primeiro, o fetichismo é uma confirmação decisiva do papel do complexo de castração. Nesse sentido, ele é uma peça importante na justificação da teoria freudiana da sexualidade. Segundo, através do fetichismo apresenta um modo peculiar de funcionamento da crença em que essa pode ser perene exatamente por dissociar-se do saber. Essa dissociação entre crença e saber implicará profundas mutações no sentido do fetichismo, tal como herdado da tradição iluminista. Por fim, o fetichismo permitirá a Freud expor um traço maior da estrutura funcional do Eu moderno, a saber, a clivagem (Spaltung). $\mathrm{O}$ reconhecimento da clivagem como fato intransponível da estrutura do Eu permitirá à posteridade psicanalítica construir as bases para uma crítica dos processos de maturação e desenvolvimento individual hegemônicos em nossa forma de vida, assim como complexificar certos aspectos importantes da teoria freudiana da mente (SAFATLE, 2010, p. 45-46).

\section{A CONTRIBUIÇÃO ZIZEKIANA AO CONCEITO DE FETICHISMO EM MARX.}

O "fetichismo da mercadoria" postulado por Marx é uma forma social fantasiosa entre as coisas definidas entre os homens. O valor de uma certa mercadoria, que é de fato a insígnia de uma rede de relações sociais entre os produtores de diversas mercadorias, assume 
a forma de uma propriedade quase "natural". O aspecto essencial do fetichismo da mercadoria não consiste na famosa "coisificação" do homem, mas em um certo desconhecimento da relação entre uma rede estruturada e um de seus elementos.

Tal fenômeno ocorre sumamente em sociedades capitalistas, em cujo sistema as relações entre os homens não são aparentemente "fetichizadas"; o que temos aqui são relações entre pessoas "livres", cada qual seguindo seu próprio interesse. A forma predominante de suas interrelações não é a dominação e a servidão, mas um contrato entre pessoas livres, supostamente "iguais perante a lei". Em outras palavras, em nossa sociedade, as "relações entre homens" são totalmente desfetichizadas, como se essas relações fossem recompensadas nas "relações entre os homens" com o fetichismo da mercadoria.

Žižek sublinha que a "forma-mercadoria" é uma espécie de a priori do conhecimento, e com isso, no ato de troca, os indivíduos procedem "como se" a mercadoria não estivesse sujeita a trocas físicas e materiais, como se ela estivesse excluída do ciclo natural da degradação, embora, no nível da "consciência", eles "saibam muito bem" que isso não acontece:

Sei muito bem, mas, ainda assim... As explicações correntes dessa fórmula ("sei que minha mãe não tem falo, mas, ainda assim... [acredito que ela o tem]", "Sei que os judeus são agentes como nós, mas, ainda assim [há qualquer coisa neles]".) devemos sem dúvida acrescentar também a variante do dinheiro: "sei que o dinheiro é um objeto material como os outros, mas, ainda assim..." [é como se ele fosse feito de uma substância especial, sobre a qual o tempo não tem nenhum poder] (ŽIŽEK, 1999, p.330).

Diante desse quadro, o que há de fetichismo no fetichismo da mercadoria? O que fazem exatamente os sujeitos quando produzem? Marx pretendia mostrar que, no interior da economia das sociedades capitalistas industriais, os sujeitos, ao produzir mercadorias, projetariam isso no sentido de não poderem mais se reconhecer naquilo que eles mesmos fazem e produzem. No ato do consumo fetichizamos não os objetos, mas a própria ação de adquirir a mercadoria, pois suas características sensíveis e físicas são negadas em prol de um determinado valor que deve ser encarnado. É esse processo "fantasmagórico" que nos permite destruir a materialidade de todo objeto singular e de todo o sensível em geral. Nesse sentido, segundo Safatle, temos a inversão daquela ideia iluminista do sujeito europeu: um sujeito que, tendo reconhecido o verdadeiro valor (de mercado) do objeto como mercadoria, se fixa nos valores transcendentais dos objetos. 


\section{A IDEOLOGIA E SEUS ESPECTROS.}

Ao contrário do "modo sintomal" — como o concebeu a tradição marxista - a ideologia atua de modo cada vez mais "fetichista". Na perspectiva marxista, o método sintomal da crítica da ideologia poderia instaurar uma universalidade sem seu sintoma. Nessa operação, a mentira ideológica que estrutura nossa percepção da realidade é ameaçada por sintomas como "retornos do recalcado"; em outras palavras, como rasgos na superfície da mentira ideológica. Já o fetiche é a personificação da mentira, é a "falsa aparência" que nos permite sustentar a verdade insuportável.

A partir dessa perspectiva, podemos entender o clássico exemplo de Žižek sobre a ideologia "fascista-populista", cuja concepção política envolve uma falsa identificação dos antagonismos presentes em nossa realidade social e, portanto, fetichiza este obstáculo na luta contra os judeus. Žižek nos dá um bom exemplo para entendermos o papel do "fetiche" neste caso:

\footnotetext{
Vejamos o caso da morte de um ente querido: o caso do sintoma, "reprimindo" essa morte, tento não pensar nela, mas o trauma reprimido retorna no sintoma; no caso do fetiche, ao contrário, aceito inteira e "racionalmente" essa morte, mas, ainda assim, agarro-me ao fetiche, a alguma característica que personifica, para mim, a desautorização da morte. Nesse sentido, o fetiche pode ter o papel muito construtivo de permitir que lidemos com a dura realidade: os fetichistas não são sonhadores perdidos em seu mundo particular, são totalmente "realistas", capazes de aceitar o modo como as coisas são porque, ao se agarrar ao fetiche, conseguem mitigar o impacto total da realidade (ŽIŽEK, 2009, p.62).
}

Ou seja, análogo a tal ideia, o ódio popular da exploração oriunda das relações capitalistas é deslocada para uma "conspiração judaica", pois quando o fascista proclama "os judeus são a causa de nosso sofrimento", o que esta por trás desse discurso é "o capital é a causa de nosso sofrimento". Nesse ponto, Žižek alerta ainda para o fato de que, nessa mistificação, necessitamos da dupla "sintoma e fetiche": o judeu é o fetiche dos antissemitas, e é ao que eles se agarram antes de confrontar a luta de classe. No procedimento sintomal e no fetiche, o papel estrutural é o mesmo: se esse elemento excepcional for perturbado, todo o sistema se desintegra.

Contudo, a reflexividade própria da ideologia cínica na contemporaneidade poderia nos levar ao abandono do conceito de fetichismo. O paradoxo central da pós-modernidade é 
que o próprio processo de produção, que estabeleceu o desvelamento de seu mecanismo, funciona como um fetiche que obnubila a dimensão crucial do seu modo de produção social.

Tomemos o caso do "fetichismo do dinheiro": o dinheiro é, na realidade, efetivamente, a encarnação de uma rede de relações sociais; sua função é uma função social, e não uma propriedade do dinheiro enquanto coisa - pois bem, essa função de ser a encarnação da riqueza, o equivalente geral de todas as mercadorias, afigura-se aos indivíduos como uma propriedade natural do dinheiro como coisa, como objeto natural - como se o dinheiro já fosse, enquanto coisa, o equivalente geral, a encarnação da riqueza (ŽIŽEK, 1992, 61).

Ou seja, o "fetichismo do dinheiro" traduz de maneira adequada o fetiche sem objeto próprio de nossos mecanismos ideológicos do capitalismo contemporâneo. Com isso, o cinismo como ideologia é uma "espectralização", a "negação da negação" que podemos encontrar na dissipação gradual do fetiche. Essa desmaterialização é o que encontramos em nossa era do "dinheiro eletrônico", em que o dinheiro perdeu sua dimensão física e tornou-se uma entidade puramente virtual, acessível com um cartão de crédito ou qualquer outro meio de informação digital.

Para o filósofo esloveno, o que debilitou a força da teoria marxista sobre a "formamercadoria" foi apartar de suas análises o caráter material "sublime" da mercadoria, isto é, a matéria "indestrutível e imutável” que pode persistir além da deterioração da matéria física. Segundo Žižek, a ideia de uma corporalidade imaterial do "corpo adentro do corpo" é que nos dá uma definição precisa do objeto sublime.

$\mathrm{Na}$ era do dinheiro eletrônico, o paradoxo encontra-se em sua "espectralização", enquanto coisa invisível que só percebemos por seus efeitos, que se tornaram mais opressivos, pois não há como os sujeitos escaparem de seu controle. Na efetividade social do mercado, tratamos as mercadorias "como se" constituíssem uma substância imutável sobre a qual o tempo não exerce nenhum poder. Mas sabemos perfeitamente que qualquer objeto material sofre os efeitos do uso, que seu corpo material se modifica ao longo do tempo. De acordo com Žižek, a circulação do capital como abstração ideológica que Marx descreveu em sua "crítica da economia política" tornou-se "real", pois não é mais uma falsa percepção da realidade social. Em nossa época, essa circulação "fetichista" do mercado financeiro determina a estrutura de processos sociais bastantes materiais, isto é, a realidade social dos indivíduos é determinada pela circulação do capital. 
Em resumo, a forma mais elevada de ideologia não reside em se enredar na espectralidade ideológica, esquecendo sua base em indivíduos reais e em suas relações, mas exatamente em deixar de lado esse Real de espectralidade e fingir abordar diretamente "pessoas reais com preocupações reais". Os visitantes da Bolsa de Valores de Londres recebem um folheto gratuito que lhes explica que o mercado de ações não trabalha com flutuações misteriosas, mas com pessoas reais e seus produtos - esse é o aspecto mais puro da ideologia (ŽIŽEK, 2010, p. 303).

\section{CONCLUSÃO}

Como podemos perceber, o fetichista é realista, ele não é um "cego" perante sua realidade efetiva; no ato da troca, o que ele desconhece é a função social da troca. Mas se os indivíduos reconhecessem essa dimensão fetichista "efetiva", a dimensão da troca não seria possível, e é através dessa atomização dos indivíduos que funcionam as produções do mercado. Ou seja, a realidade social é composta e sustentada por esse "não-conhecimento" de sua essência ontológica, pois se soubéssemos de seu "verdadeiro" funcionamento, ela se dissolveria. Como já vimos, a ilusão é o fio condutor do vinculo social, e é por esse fator que não saímos da dimensão fundamental da ideologia. Não há uma "falsa consciência" ou a “desrazão da própria razão", mas uma representação ilusória da realidade, que já deve ser concebida como ideológica. Nas palavras de Žižek:

\footnotetext{
"ideológica" é uma realidade social cuja própria existência implica o nãoconhecimento de sua essência por parte de seus participantes, ou seja, a efetividade social cuja própria reprodução implica que os indivíduos "não sabem o que fazem". "Ideológica" não é uma falsa consciência de um ser (social), mas esse próprio ser, na medida em que ele é sustentado pela "falsa consciência". Chegamos finalmente à dimensão do sintoma, pois uma de suas definições possíveis seria, igualmente, "uma formação cuja própria consistência implica um certo não-conhecimento por parte do sujeito": o sujeito só pode "gozar com seu sintoma" na medida em que sua lógica lhe escapa - a medida do sucesso da interpretação do sintoma é, precisamente, sua dissolução (ŽIŽEK, 1999, p.306).
}

Para Žižek, a tradição hegeliano-marxista concebe a ideologia como "consciência falsa", determinada pela objetividade "reificada" do processo social alienado: seu modelo básico são as "formas objetivas de pensamento", que se formam contra o fundo do "fetichismo da mercadoria", na produção capitalista avançada. Em decorrência dessa visão, a expectativa é que a crítica faça com que "a substância se torne sujeito", que o sujeito se liberte da “dominação heterônoma de seu próprio inconsciente" - inconsciente este pensado como 
história alienada, como processo histórico governado por leis que se fazem valer "pelas costas" dos sujeitos. (ŽIŽEK, 1992, p. 35).

Contudo, o encantamento fetichista é um "saber" impotente diante da crença. Segundo Žižek, tomamos cerveja sem álcool como se ainda fosse cerveja, café sem cafeína como se ainda fosse café, somente para não confrontarmos os valores e costumes de nossa cultura. Desse modo, trata-se de retirar da coisa a substância ativa, a propriedade nociva, o que faz com que ela seja o que é. Já da crença, como bem observou Safatle, retiramos o que a faria funcionar, ou seja, “o fato de aderirmos a ela para valer” (SAFATLE, 2010, p.19).

\section{REFERÊNCIAS}

Žižek, Slavoj. Em defesa das causas perdidas. Trad. Maria Beatriz Medina. São Paulo: Boitempo, 2011a.

. Primeiro como tragédia, depois como farsa. Trad. Maria Beatriz Medina São Paulo: Boitempo, $2011 b$.

. Um mapa da ideologia. Trad. Vera Ribeiro. Rio de Janeiro: Contraponto, 1999.

. Bem-vindo ao Deserto do Real. Trad. Paulo César Castanheira. São Paulo: Boitempo, 2005.

. "Fétichisme et subjectivation interpassive" in: Actuel Marx. Paris, PUF, n.34, 2003.

. Eles não sabem o que fazem: o sublime objeto da ideologia. Trad. Vera Ribeiro. Rio de Janeiro: Jorge Zahar, 1992.

O mais sublime dos histéricos: Hegel com Lacan. Rio de Janeiro: Jorge Zahar,1991.

ADORNO, T. \& HORKHEIMER, M. Dialética do Esclarecimento: fragmentos filosóficos. Trad. Guido Antonio de Almeida. Rio de Janeiro: Jorge Zahar, 2006.

AGAMBEN, G. Estado de Exceção. Trad. Iraci D. Poleti. São Paulo: Boitempo, 2007.

BENJAMIN, W. Obras Escolhidas II: Rua de mão única. Trad. Rubens Rodrigues Torres Filho e José Carlos Martins Barbosa. São Paulo: Brasiliense, 1995.

EAGLETON, T. A Ideologia da Estética. Trad. Mauro Sá Rego Costa. Rio de Janeiro: Jorge Zahar, 1993. 
SAFATLE, V. Cinismo e falência da crítica. São Paulo: Boitempo, 2008.

Fetichismo: colonizar o outro. Rio de Janeiro: Civilização Brasileira, 2010.

SLOTERDIJK, P. Crítica da Razão Cínica. Trad. Marco Casanova. Rio de Janeiro: Estação liberdade, 2013.

MARCUSE, H. "Sobre o caráter afirmativo da cultura". In: Cultura e Sociedade. Trad. Wolfgang Leo Maar. São Paulo: Paz e Terra, 1997, v. 1.

1973.

Contra-revolução e Revolta. Trad. Álvaro Cabral. Rio de Janeiro: Jorge Zahar,

. Eros e Civilização: uma interpretação filosófica do pensamento de Freud. Trad.

Alvaro Cabral. Rio de Janeiro: Zahar, 1981.

MARX, K. O Capital: crítica da economia política. Trad. Régis Barbosa e Flávio R. Kothe. São Paulo: Nova Cultural, 1996. (Livro 1, vol. I)

FREUD, S. "Três ensaios sobre a teoria da sexualidade". In: Edição Standard Brasileira das Obras Psicológicas Completas de Sigmund Freud, vol. VII. Rio de Janeiro: Imago, 1987a.

"Fetichismo". In: Edição Standard Brasileira das Obras Psicológicas Completas

de Sigmund Freud, vol. XXI. Rio de Janeiro: Imago, $1987 \mathrm{~b}$.

. "Divisão do ego no processo de defesa". In:Edição Standard das Obras

psicológicas completas de Sigmund Freud, vol. XXIII. Rio de Janeiro: Imago, 1987c. 